\title{
Sobre "ser mulher e mãe" em situação de rua: invisibilidade na sociedade brasileira
}

\author{
On being a homeless 'woman and mother': \\ invisibility in Brazilian society
}

\author{
Tabita Aija Silva Moreira* \\ Carmem Plácida Sousa Cavalcante** \\ Deyze da Silva Ferreira*** \\ Ilana Lemos de Paiva****
}

\begin{abstract}
Resumo - Este estudo apresenta como objetivo averiguar a vivência da gravidez por um casal de mulheres em situação de rua no município de Natal (RN). Trata-se de uma investigação de cunho social, cuja metodologia é definida por um estudo de caso, no qual foi utilizada a entrevista em profundidade. A literatura aponta que estas mulheres são invisibilizadas pelas políticas, sendo vistas apenas quando há associação com drogas ou criminalidade. A vivência da gestação é permeada por estigmas e preconceitos que reforçam a crença da sociedade, na incapacidade delas para exercerem a maternidade. Assim, o Estado, operando sob o modo de produção capitalista, apresenta mais mecanismos para a separação entre mãe e bebês do que de apoio para a superação da situação de rua. Os resultados sugerem que estas mulheres se organizam junto à família, aos movimentos
\end{abstract}

\footnotetext{
* Doutoranda pelo Programa de Pós-graduação em Psicologia da Universidade Federal do Rio Grande do Norte (UFRN) na linha de pesquisa Psicologia e Práticas Sociais. Com período de estágio na Universidade de Salamanca (USAL) e bolsa do Programa Institucional de Internacionalização da Coordenadoria de Aperfeiçoamento do Ensino Superior (CAPES/PrInt). E-mail: tabita.smoreira@gmail.com. ORCID: https://orcid.org/0000-0001-6913-4160.

** Doutoranda pelo Programa de Pós-graduação em Psicologia da Universidade Federal do Rio Grande do Norte (UFRN). Psicóloga colaboradora no Centro de Referência em Direitos Humanos (UFRN). Membro do Observatório da População Infanto-juvenil em contextos de violência (OBIJUV) e do Grupo de Pesquisa Marxismo e Educação (GPM\&E). Coordenadora da Comissão de Direitos Humanos do Conselho Regional de Psicologia do RN. Atualmente, docente (substituta) do Departamento de Psicologia da UFRN. E-mail:carmempscavalcante@gmail.com. ORCID:https://orcid.org/ 0000-0001-8793-900X.

*** Psicóloga (UFRN). Mestranda pelo Programa de Pós-graduação em Psicologia da UFRN, bolsista CNPq. Especialista em Psicologia da Saúde: Desenvolvimento e Hospitalização pela UFRN. Membro do Grupo de Pesquisa Marxismo e Educação (GPM\&E) e do Observatório da População Infantojuvenil em Contextos de Violência (OBIJUV). Possui experiência em docência no ensino superior na área da Psicologia da Educação, pelo Departamento de Fundamentos e Políticas da Educação (DFPE), do Centro de Educação (CE) da UFRN. E-mail: deyze.silfer@gmail.co. ORCID: https:/ /orcid.org/0000-0002-5324-3378.

**** Professora doutora associada do Departamento de Psicologia da Universidade Federal do Rio Grande do Norte. Coordenadora do Observatório da População Infantojuvenil em Contextos de Violência (OBIJUV/UFRN). Pesquisadora associada ao Grupo de Pesquisa Marxismo e Educação (GPM\&E). Bolsista de Produtividade do CNPq (nível 2). E-mail: ilanapaiva@hotmail.com. ORCID: https://orcid.org/0000-0002-3331-2890.
} 
\} SOBRE "SER MULHER E MÃE" - MOREIRA, T. A. S.; CAVALCANTE, C. P. S.; FERREIRA, D. S.; PAIVA, I. L. \} DOI: $10.12957 /$ rep.2021.56078

sociais e às redes de solidariedade para resistirem à separação de seus filhos.

Palavras-chave: mulheres em situação de rua; maternidade; homomaternidade; direitos sexuais e reprodutivos; políticas públicas.

\begin{abstract}
This study aims to investigate the experience of pregnancy by a same-sex couple of homeless women in the city of Natal, Rio Grande do Norte. This is a social investigation, whose methodology is defined by a case study, in which the in-depth interview was used. The literature points that these women are made invisible by policies, being seen only when associated with drugs or crime. The experience of pregnancy is permeated by stigmas and prejudices that reinforce society's belief in their inability to exercise motherhood. Thus, the State, operating under the capitalist mode of production, presents more mechanisms to separate mother and children than to help them overcome their homelessness. The results suggest that these women organize themselves with family, social movements, and solidarity networks to resist the separation from their children.

Keywords: homeless women; maternity; homomaternity; sexual and reproductive rights; public policy.
\end{abstract}

\title{
Introdução
}

A forma como se estrutura a sociedade atual é definida pelo domínio do capital. Além disso, é regida pelos princípios do liberalismo econômico, ou seja, pelos ideais de liberdade, igualdade e propriedade, cujo pressuposto é a existência de um mercado no qual aparecem dois personagens na cena social: o trabalhador e o capitalista. Esse último é o detentor dos meios de produção, o proprietário; o primeiro, aquele que vende a sua única fonte de renda, sua força de trabalho (SAVIANI, 2013).

A sociedade capitalista, portanto, é composta por classes com interesses antagônicos. Nela é produzido um exército de reserva, que consiste na população que busca sua sobrevivência no subemprego ou em relações precarizadas de trabalho. A população em situação de rua ocupa os espaços ainda mais segregados no cenário social, pois dela são retirados os direitos de existir, cuja marca principal é a sua invisibilidade. São pessoas que, por não terem garantido o acesso a um trabalho que lhes proveja condições mínimas de dignidade, acabam vivendo da mendicância, ocupando os espaços públicos e, muitas vezes, sendo criminalizadas por não "caberem" no cinturão proposto pelo capitalismo.

Diante disso, as sociedades capitalistas têm enfrentado problemas sociais decorrentes de suas próprias contradições. "Sobram" pessoas num processo de inclusão perversa, pois este sistema as exclui dos bens de produção e de consumo para, em seguida, incluí-las através da escassez ou mesmo ausência total de recursos como princípio de sobrevivência (MARTINS, 1997). A população em situação de rua (Pop Rua/PSR) faz parte do cenário que compõe o fenômeno inerente à produção capitalista das 


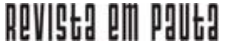

\} SOBRE "SER MULHER E MÃE" - MOREIRA, T. A. S.; CAVALCANTE, C. P. S.; FERREIRA, D. S.; PAIVA, I. L. \}

DOI: $10.12957 /$ rep.2021.56078

cidades, cujo acesso também lhe é negado. Desse modo, não há espaço para estas pessoas nem mesmo nas ruas, pois estas passam por processos constantes de higienização, estigmatização e interdição (BRASIL, 2009). De acordo com a Política Nacional para a População em Situação de Rua (PNPR):

considera-se população em situação de rua o grupo populacional heterogêneo que possui em comum a pobreza extrema, os vínculos familiares interrompidos ou fragilizados e a inexistência de moradia convencional regular, e que utiliza os logradouros públicos e as áreas degradadas como espaço de moradia e de sustento, de forma temporária ou permanente, bem como as unidades de acolhimento para pernoite temporário ou como moradia provisória (BRASIL, 2009, n. p.).

É possível perceber que a população em situação de rua é caracterizada por sua diversidade para a PNPR. Assim, este artigo parte dos pressupostos da teoria social marxiana, segundo a qual o real só pode ser apreendido por meio da primazia da concreticidade. Neste sentido, as mulheres, segmento produtor e, ao mesmo tempo, explorado pelo ciclo capital-trabalho, não são apenas trabalhadoras nas sociedades capitalistas, mas exercem um papel fundamental na reprodução humana como fonte de criação de valor e exploração. Essas sociedades se estabeleceram, em grande parte, devido ao trabalho não remunerado das mulheres como mães responsáveis pela reprodução biológica e social de trabalhadores assalariados para garantir a produtividade do sistema. O desenvolvimento da sociedade capitalista prescinde, então, da ascensão do patriarcado, em concomitância com o aprofundamento das relações sociais de raça, além do cerceamento dos direitos políticos, sexuais e reprodutivos das mulheres. É através da idealização da família burguesa, que a maternidade se constrói associada ao papel da mulher como mãe protetora e totalmente dedicada à família.

Faz-se necessário entender as relações patriarcais de gênero que perpassam a existência da mulher antes mesmo do modo de produção capitalista, mas que com ele se acirram e se aprofundam, associando-se às categorias sociais de raça e classe, uma vez que a construção social da PSR no Brasil tem relação direta com a escravização. Cabe destaque à apropriação do corpo, da vida e da força de trabalho das mulheres pelos homens. O operário só poderia ofertar, trocar e vender ao mercado a sua capacidade de trabalho e produção, haja vista que, segundo Guillaumin (2004, p. 33), "o corpo é reservatório da força de trabalho". No caso das mulheres, ocorre a exploração de sua força de trabalho por vezes sem remuneração, principalmente no trabalho reprodutivo e doméstico. Nesse caso, não é só a força de trabalho que é explorada, mas a própria "máquina", a mulher em si, por meio da apropriação física direta (relações de sexo, escravidão e servidão). 
Destacamos as mulheres em situação de rua (MSR) por estarem expostas a diversas formas de violência e por travarem constante luta pela sobrevivência. Ao vivenciar a gestação, essas mulheres não encontram condições suficientes para o exercício da maternidade pela falta de políticas públicas que as amparem e protejam da violência. Há uma realidade nacional de casos de retiradas compulsórias de bebês, ainda na maternidade, de mães em situação de rua e/ou usuárias de drogas (CONANDA, 2017; MALHEIRO, 2018). Outrossim, estão expostas a casos como o que ocorreu em Mococa, interior de São Paulo, onde foi deferido judicialmente o procedimento de esterilização de uma mulher por ser classificada como "dependente química" e, assim, incapaz de ser mãe ${ }^{1}$. Essas situações evidenciam um recorte de classe na autorização social e jurídica para o exercício da maternidade. Dito isso, faz-se relevante ouvir essas mulheres sobre a vivência da gravidez no contexto da vivência de rua e suas estratégias de enfrentamento aos desafios gestacionais e à violência.

\section{Metodologia}

A proposta da presente pesquisa é averiguar a vivência da gravidez por um casal homoafetivo de mulheres em situação de rua (MSR) no município de Natal (RN). Para a construção dos dados da presente pesquisa, utilizamos uma abordagem metodológica que compreendeu uma observação participante e entrevista em profundidade.

Neste sentido, elucidamos questões acerca da sociedade atual que afetam diretamente o empobrecimento das mulheres. Enfatizamos que esta pesquisa reconhece os problemas sociais e pretende proporcionar reflexão sobre eles (GROULX, 2010). Tendo como referencial o materialismo histórico-dialético, compreendemos o objeto pesquisado como parte de uma totalidade complexa, considerando que as contradições do sistema capitalista se colocam como empecilho para a efetiva garantia dos direitos do segmento populacional em questão. Este referencial introduz elementos de análise contextualizados, podendo descortinar a essência dos problemas sociais para além das aparências.

Ao observar o fenômeno da Pop Rua como expressão direta do Estado sobre estes sujeitos, é importante dar vazão a uma discussão dialética dentro do plano de análise. O Estado, como um aparelho central e exclusivo de poder (MACHADO, 1979) expressa visivelmente sua ação sobre a vida em sociedade. Com isso, percebemos a possibilidade de discutir os dados a partir de um ponto de vista que revela as expressões de saber e poder dentro da sociedade, acabando por proporcionar uma desfiliação dos sujeitos dentro do seu próprio meio social.

${ }^{1}$ Disponível em: https://brasil.elpais.com/brasil/2018/06/12/politica/1528827824_974196.html. Acesso em: 6 fev. 2020. 
\} SOBRE "SER MULHER E MÃE" - MOREIRA, T. A. S.; CAVALCANTE, C. P. S.; FERREIRA, D. S.; PAIVA, I. L. \}

DOI: $10.12957 /$ rep.2021.56078

Este trabalho é parte de uma pesquisa maior sobre gravidez e maternidade de mulheres que estão em situação de rua no município de Natal (RN), cuja ideia central é problematizar as possibilidades de ser família em situação de rua diante de um cenário de criminalização e judicialização da pobreza. Assim, através da observação participante em reuniões e eventos organizados pelo Movimento Nacional População de Rua do Rio Grande do Norte (MNPR/RN) e por organizações parceiras conhecemos os sujeitos de pesquisa, Mamusca e $\mathrm{P}^{2}$. O casal foi convidado a participar da pesquisa, na qual foi realizada entrevista em profundidade - individual e em conjunto -, gravada com a autorização das mesmas e com anuência do Comitê de Ética e Pesquisa da Universidade Federal do Rio Grande do Norte. Após a transcrição da entrevista, foi realizada a análise temática dos resultados de acordo com o proposto por Braun e Clarke (2006).

\section{Resultados e discussão ${ }^{3}$}

\section{"Bom... Mulheres da rua, sim!"}

Conhecemos Mamusca em julho de 2018, durante um evento mobilizador proposto pelo Conselho Regional de Psicologia do Rio Grande do Norte (CRP 17/RN) em resposta a denúncias sobre retiradas compulsórias de bebês das suas mães ainda na maternidade. O tema do encontro foi $O$ ECA e os impactos da integralidade na proteção de famílias em situação de rua por ser, também, alusivo aos 28 anos do Estatuto da Criança e do Adolescente. Participaram desta atividade representantes do Sistema de Garantia de Direitos das Crianças e Adolescentes (SGDCA) secretarias municipais de assistência social e saúde, defensoria pública, universidade e coletivos de defesa dos direitos humanos, como o MNPR/RN.

Os apontamentos indicaram que a garantia do direito à convivência familiar das crianças em situação de rua demanda ações integradas e contínuas que promovam a garantia de direitos como habitação e acesso ao trabalho aos seus pais. Contudo, o atendimento à infância no município parece priorizar a destituição do poder familiar diante da ausência de ações que garantam o atendimento integral a estas famílias.

Neste evento, uma fala de Mamusca chamou a atenção: "por que não faz uma casa pra essas mulheres ficarem com os filhos?". Este questionamento levanta a reflexão sobre a não autorização das famílias pobres de poderem se constituir como família, pois os instrumentos sociais e jurídicos existentes priorizam a sua separação. Cerca de um ano depois, reencontramo-nos durante o I Seminário Não somos invisíveis: políticas públicas

\footnotetext{
${ }^{2}$ Nomes fictícios, escolhidos pelas próprias entrevistadas.

${ }^{3}$ Os subtítulos desta seção foram retirados do poema Mulher da rua, de Luanda Luz (2019), que compõe a liderança do MNPR/RN, disponível em: https://repositorio.ufrn.br/jspui/handle/123456789/28193.
} 
\} SOBRE "SER MULHER E MÃE" - MOREIRA, T. A. S.; CAVALCANTE, C. P. S.; FERREIRA, D. S.; PAIVA, I. L. \} DOI: $10.12957 /$ rep.2021.56078

para a população em situação de rua do Rio Grande do Norte, promovido pela Secretaria de Estado das Mulheres, Juventude, Igualdade Racial e Direitos Humanos, em parceria com outras instituições, com foco nos trabaIhadores e trabalhadoras da assistência social e saúde. A cada fala, o MNPR/ RN questionava as autoridades sobre a garantia dos seus direitos, fazendo valer um dos seus lemas: "Nada sobre nós, sem nós!". Mamusca reivindicava melhores condições para as mães criarem seus filhos junto a outras mulheres em situação de rua (MSR). Na ocasião, P1, sua companheira, estava grávida de quatro meses. Poucos dias depois, realizamos a entrevista aqui discutida.

Mamusca é uma mulher negra de 34 anos, com vivência de rua há dez anos. Atualmente, é uma das líderes do MNPR/RN que tem como base "uma relação orgânica com apoiadores que lutam por direitos humanos, destacando atividades contínuas de formação para a participação política, de geração de trabalho e renda com base na Economia Solidária" (VERGARA, 2019, p. 112). Em sua fala, fica evidente a não dissociação do seu lugar como mulher e líder do movimento, pois esta função, para ela, consiste num modo de existir e de se tornar visível nas ruas, lutando contra as violências da sociedade e do Estado que afeta seus ou suas companheiros/ as.

Ela está há um ano em um relacionamento sério com P1, 29 anos, e que se encontra há 11 anos nas ruas devido à dependência química, principalmente após a perda de sua mãe, que ocorreu há seis anos. Elas já se conheciam há cerca de dez anos e há um ano estavam em um relacionamento estável. Mamusca já tinha dois filhos e uma filha de relacionamentos anteriores, com 17, 15 e 14 anos, respectivamente. Os adolescentes são cuidados por familiares e, para ela, foi uma opção melhor do que estarem na rua com ela ou serem adotados, pois assim pode manter o contato com os filhos. "[...] eles vêm me ver, dão cheiro e tal e eu vou lá" (Mamusca). Sobre a adoção, ela é enfática: "Deus me livre! Quando tiver um canto eu vou buscar eles tudinho de novo, é assim" (Mamusca).

Falar sobre os filhos não foi fácil para Mamusca; foi um relato com emoções que ela preferiu não aprofundar. A entrega de um filho/a aos cuidados dos familiares e/ou vizinhos e amigos é uma prática conhecida tanto entre famílias rurais, como em periferias dos grandes centros urbanos. Constitui-se numa estratégia de cuidado e preservação dos laços para evitar a institucionalização. Além disso, pode ser compreendida como uma estratégia das famílias negras brasileiras frente às ações do Estado racista, pois sua origem remonta a tradições africanas em que "a criança não é vista como objeto ou mercadoria, mas sim como um filho de todos os integrantes do grupo familiar" (SARAIVA, 2019, p. 86). Apesar disto, essas famílias nem sempre são reconhecidas pelos poderes públicos, pois não correspondem ao ideal burguês de família nuclear. Além disso, as mães que realizam estes arranjos são comumente taxadas como "aquela que abandonou o filho", sem que se considere sua intenção de prover cuidado dentro das 
\} SOBRE "SER MULHER E MÃE" - MOREIRA, T. A. S.; CAVALCANTE, C. P. S.; FERREIRA, D. S.; PAIVA, I. L.

DOI: $10.12957 /$ rep.2021.56078

suas possibilidades e o seu próprio histórico de abandonos e violências vividas. Os pais dos filhos de Mamusca e P1, por exemplo, não aparecem nos seus relatos.

A gravidez do casal não foi planejada, resultou de uma violência sexual perpetrada enquanto P1 dormia sob efeito de um remédio de uso contínuo com ação sedativa. Na ocasião, elas tinham conseguido alugar um quarto, porém foi invadido pelo abusador em uma noite em que Mamusca estava visitando sua família. De acordo com ela, não foi uma situação isolada para as MSR, exemplificando como a mulher está exposta e como pode ser objetificada e apropriada pela classe dos homens não só nas dificuldades de acesso ao mercado de trabalho, mas também na demonstração de força, na coação sexual e no direito usual destinado a esta população (GUILLAUMIN, 2014).

P1 estava na quarta gestação e, a despeito de esta última ser oriunda de violência sexual, o fato de ter perdido três filhas de gestações anteriores a mobiliza a cuidar da filha que estava gestando e de si mesma. Como consequência: "nas outras gestações que eu tive, eu não sentia nada, porque eu tava usando droga... essa não... Porque eu quis o bem da minha nenê, porque as outras faleceu, por conta da droga. Quando nascia, morria, por conta da droga" (P1). Semelhante a Mamusca, P1 encontrou alguém que cuidasse de uma das filhas, porém a criança faleceu aos cinco anos por problemas respiratórios. Por duas vezes, P1 foi internada em comunidades terapêuticas (CTs) com a ajuda da sua mãe e, depois, de um grupo de amigas. Entretanto, a experiência deixou um sentimento de frustração. Sobre esta situação, ela relata:

Eu acho esses negócios de casa de apoio, não dá jeito não. Porque eles querem obrigar a gente a ser uma coisa que nós não somos ainda. É porque lá tem regras, tem que acordar cedo, tem que não sei o quê. Então, acho que casa de recuperação, era pra ser uma casa que nós se habilitasse a fazer as coisas por nossos interesses, não por obrigação de ser todo dia [...] Quando nós volta a sensação de querer fumar mais é maior (P1).

As CTs estão na contramão dos mecanismos da reforma psiquiátrica, mas são consideradas alternativas prioritárias para a Pop Rua, ao lado dos hospitais psiquiátricos. As regras rígidas dos locais, associadas às práticas fundamentadas na abstinência, provocam a fuga após poucas semanas na maioria dos casos, "pois afirmam se sentirem 'presos' ou percebem que os espaços não são eficientes no tratamento" (ARRAES AMORIM et al., 2019, p. 148). Mamusca complementa: "aí só que, o que foi que ela disse: 'você vai pra João Pessoa e você fica aqui!' Então, o que elas queriam: elas querem nos separar, tem um certo preconceito".

Nota-se que as CTs estão pautadas em regras que interferem no direito básico à convivência familiar e comunitária e têm grupos con- 
servadores como mantenedores. Tal fato contribui para visões específicas do que é família, não reconhecendo as pluralidades da sua constituição, como aponta P1: "porque o juiz não já assinou, né? O padre (Papa) não já aceita? Por que que as casas de apoio não tão aceitando?".

A literatura aponta que as MSR revelam que o uso abusivo de substância psicoativas está relacionado a tentativas de esquecer experiências de violência e humilhação (MALHEIRO, 2018). O uso de drogas, entretanto, deixa-as mais suscetíveis a sofrerem algum tipo de violação, duas a cinco vezes mais do que as demais mulheres (DIAS, 2019). Neste cenário, a gravidez demanda maior esforço para garantir sua proteção, cuidados de saúde, dentre outras necessidades deste período.

\section{“Mães, tias e filhas... Sou diferente não, mulher!"}

A gestação provoca uma série de transformações na vida da muIher, como as corporais e as de humor. À medida que a gravidez avança, a rotina da mulher vai se modificando, desde a posição para dormir, as relações sexuais e das atividades miccionais. São aspectos que atingem todas as mulheres, mas para aquelas que estão no contexto da rua a gestação pode ser considerada mais um fator de vulnerabilidade social ${ }^{4}$ devido à possível precariedade das condições de vida e à dificuldade de acesso aos serviços de saúde. Por outro lado, pode ampliar as possibilidades de produção de redes de apoio e assistência (COSTA et al., 2015) e resgatar o autocuidado das mulheres, especialmente as que possuem dependência química (KUYAVA, 2013; RIOS, 2017).

A gestação no contexto da situação de rua é considerada vulnerável por expor cada vez mais estas mulheres. A trajetória de ruptura e quebra de vínculos também torna mais difícil sua adesão a tratamentos de saúde e acompanhamentos socioassistenciais (RIOS, 2017). Além disso, a possibilidade real de perder o poder familiar sobre o filho recém-nascido após procurar o serviço de saúde, é outro componente que tende a afastar as gestantes do acompanhamento pré-natal (BORTOLI, 2016). Este cenário revela que, ao engravidar, a vulnerabilidade da mulher em situação de rua pode ser ainda mais amplificada ao ponto de lhe ser negado o direito de ser mãe, ao mesmo tempo em que os direitos dos seus filhos começam a ser violados ainda no ventre, quando sequer a nutrição adequada é garantida.

A gestação de $\mathrm{P} 1$ parece contribuir para fortalecer seus vínculos familiares com a companheira, pois desde o falecimento da mãe ela não constituía laços familiares. P1 era filha única e a perda de sua mãe significou, também, a perda do acesso a uma moradia estável, como relata: "porque

${ }^{4} \mathrm{O}$ conceito de vulnerabilidade social engloba situações de precariedade para além da baixa renda, como a fragilização de vínculos afetivos, tanto os relacionais como os de pertencimento, decorrentes também das discriminações etárias, étnicas, de gênero ou por deficiências, dentre outras (CRONEMBERGER; TEIXEIRA, 2013, p. 19). 
\} SOBRE "SER MULHER E MÃE" - MOREIRA, T. A. S.; CAVALCANTE, C. P. S.; FERREIRA, D. S.; PAIVA, I. L. \}

DOI: $10.12957 /$ rep.2021.56078

quando eu tinha minha mãe, as coisas eram mais fáceis pra mim. Eu tinha casa, eu tinha alimentação, meus negócios, né? Minhas roupinha direitinho, tudo, tudo!" (P1). A fala de P1 desmistifica a ideia de que os jovens vivenciam a rua necessariamente devido à violência intrafamiliar, criminalizando as famílias pobres pelas rotas de vida dos seus filhos/as que não são socialmente aceitáveis.

De acordo com Mamusca: "se a mulher 'tiver' na rua, eles tomam na maternidade, não deixam nem a mulher se explicar, se vai pra casa da família, se vai pra casa de um ente familiar. Claro, que nós 'tamos' na rua, mas nós temos família. Tem sim como cuidar do seu filho". Na semana da entrevista, uma companheira havia sido separada do bebê recém-nascido e Mamusca relatou sua preocupação, pois, devido à revolta, a mãe estava usando mais drogas do que o habitual: "revoltada, se drogando, bebendo, por quê? Porque isso aí é muito doloroso. Isso é doloroso, tomar o seu filho da sua própria mãe". A saúde mental da mulher pode ser prejudicada diante de tantas violações, além das que ela já vivenciava antes da perda do filho. Algumas relatam que a retirada arbitrária do seu bebê pode aumentar o consumo do crack como forma de lidar com o sentimento "de vazio oriundo da retirada do filho/a recém-nascido/a da maternidade" (MALHEIRO, 2018, p. 231).

Caldeira (2019) discute a influência da produção da "verdade médica", visto que reduz ao uso do crack os problemas de saúde que os filhos das usuárias possam ter, sem considerar outras situações vivenciadas por elas, como a extrema pobreza, a violência, a desnutrição, dentre outras - uma abordagem descontextualizada que culpa unicamente a mulher pela vulnerabilidade da criança e reforça a crença de sua incompetência no exercício da maternidade.

A separação do filho/a é vivenciada como um novo parto e requer a elaboração do luto e de muito apoio para essa mãe ou família. Pode provocar a "gravidez de repetição" na busca por reparar a perda. Esta nova gravidez "pode significar escolha; pode significar perda; pode significar trauma; pode significar repetição; pode significar injustiça; pode significar separação e pode significar elaboração" (RIOS, 2017, p. 70). Na medida em que novas gestações são desenvolvidas e a mulher depara-se novamente com a não garantia de direitos, a destituição do poder familiar reverbera no sentimento de fracasso materno, para si e para a sociedade.

Mamusca e P1 nutrem o desejo de permanecer com o bebê que já tem nome, mas as alternativas de políticas sociais para as MSR em Natal (RN) são restritas. Não há serviços de acolhimento de longa permanência para adultos e famílias em Natal. O único serviço de acolhimento disponível só funciona no período noturno, não sendo suficiente para a quantidade de pessoas que necessitam, além de não dispor de quartos privativos para casais. O Centro de Referência Especializado para a População em Situação de Rua (Centro Pop) também não possui recursos para atender às neces- 
sidades desta população, estando restrito ao período diurno e dias úteis, enquanto as demandas da Pop Rua são constantes e diferenciadas.

Esse contexto coloca para o casal a iminência de recorrer a outras formas de apoio, como a solidariedade comunitária e a família: "A gente vai ver aí como é que vai fazer, vai manguear, quando tiver bem pertinho a gente manguêa. A gente faz qualquer coisa, mas não 'vamo deixá' não. A gente vai pra casa da família antes de nascer, com certeza" (Mamusca). Manguear é pedir dinheiro nos sinais de trânsito como forma de sobrevivência, assim como ir para a casa de parentes, uma saída temporária para evitar a separação da filha. Por outro lado, há consciência de que sua família precisa e tem direito a mais: "então a minha pauta é essa, chega de omissão, queremos educação, trabalho, ou seja, uma casa de acolhimento pra família" (Mamusca).

Na Região Metropolitana de Natal (RN), os serviços de acoIhimento de crianças e adolescentes ficam em locais distantes dos bairros das famílias de origem e de difícil acesso via transporte público. Assim, essas famílias estão vulneráveis à falta de condições para arcar com o transporte para as visitas, bem como compreender as sinuosidades de um processo jurídico, como o local do fórum, o acesso à defensoria pública e a importância da participação nas audiências. Este não saber é interpretado como falta de interesse pela criança, sem que se leve em conta as falhas do Estado em prover suporte às mães e às suas famílias no cuidado dos filhos. Romper este cenário é um desafio que demanda estratégias progressistas de efetivação de políticas públicas afirmativas e emancipadoras que valorizem e respeitem as mulheres em situação de rua, pois é especialmente sobre elas que recaem as implicações sociais e psicológicas da luta por permanecer com os/as filhos/as, ainda que diante das vicissitudes do viver na rua.

\section{"Se sonhavam? Sim. E como sonhavam!"}

Nas sociedades capitalistas, o exercício da maternidade é colocado como algo natural e instintivo do gênero feminino. Por outro lado, a experiência da gestação pode ser percebida de forma diferente pelas mulheres, não só por variáveis psíquicas, mas também pelo próprio contexto em que vivenciam a gravidez. Ela pode provocar sentimentos diversos, como revolta e tristeza pelo temor de não conseguir criar a criança diante da pobreza, bem como pela ampliação das dificuldades de sobrevivência e da dependência de serviços públicos (COSTA et al., 2015), ademais do luto por não ter podido permanecer com os filhos de gestações anteriores.

Para P1, a gravidez traz a memória afetiva da mãe, a quem tem como referência para a maternidade e se emociona ao falar: "mãe é tudo. A palavra mãe, não tem explicação não. É uma coisa importantíssima em 
\} SOBRE "SER MULHER E MÃE" - MOREIRA, T. A. S.; CAVALCANTE, C. P. S.; FERREIRA, D. S.; PAIVA, I. L. \}

DOI: $10.12957 /$ rep.2021.56078

nossas vidas, é tudo, mãe é coisa que não tem, não tem como explicar". Além disso, há a expectativa de ser mãe após tentativas anteriores: "eu ainda não me vejo (como mãe), porque eu não tive criado nenhuma. Essa eu vou criar (P1)". Ademais, demonstra preocupações concretas sobre o futuro da filha: "ah, uma mãe que tenha responsabilidade, que saiba ensinar, dar educação, porque não é só na escola. É dentro de casa, também é na vida, né? Educação pro filho. É muito complicado, é os estudos, é tudo".

A literatura aponta que a gravidez pode dar um novo significado à vida das mulheres em situação de rua, assim como poder ter um vínculo genuíno com alguém (GONTIJO; MEDEIROS, 2008), maior autocuidado para proteger a criança e buscar pelo abandono do consumo de substâncias químicas (KUYAVA, 2013; RIOS, 2017). Além disso, durante a gestação, a mulher pode planejar sua vida em termos de futuro, talvez pelo fato de receber mais cuidados e estar menos suscetível à violência (MALHEIRO, 2018). A gestação é, assim, um período ainda mais crítico para a promoção da garantia dos direitos das mulheres em situação de rua. Nas falas de Mamusca sobre o futuro, é perceptível que a luta pelos direitos da sua família se entrelaça com os direitos de outras MSR:

Um futuro, fora das ruas. Quero uma casa, por isso que a minha pauta hoje é: chega de omissão queremos habitação e trabalho pra sair dessa situação! Quero dar uma vida a ela, que eu não dei aos meus filhos [...]. A minha preocupação é mais sobre mulheres como nós que tem família como nós, que têm crianças que são tomadas.

Ela fala com orgulho sobre ser conhecida como "mãe da rua" e sobre seu desejo de "criar com muito carinho e amor, se não tomarem, né? De mim". A Nota Técnica Conjunta (NTC) MDS n. 001/2016 (BRASIL, 2016) trata de diretrizes, fluxo e fluxograma para a atenção integral às mulheres e adolescentes em situação de rua e/ou usuárias de álcool e/ou crack/outras drogas e seus filhos/as recém-nascidos/as com o objetivo de estabelecer a primazia do cuidado às mães sobre a judicialização. Prevê que as mães que desejam permanecer com os filhos podem ser incluídas em unidade de acolhimento conjunto.

Estes serviços, ao possibilitarem o convívio da mãe com o/a filho/ a, abrem espaço para uma ruptura do círculo de quebras de vínculos que caracterizam a vida delas, bem como criam um espaço seguro para o desenvolvimento da maternidade (GONTIJO; MEDEIROS, 2008). Entretanto, ainda são restritos a alguns municípios ou estados e há falta de vagas suficientes. Além disso, os serviços de acolhimento conjunto ainda carecem de normas horizontais sobre quem será acolhido (GOMES, 2018); assim, há uma priorização no acolhimento de crianças sobre o acolhimento conjunto e manutenção dos vínculos familiares. Desse modo, há uma desconformidade com a excepcionalidade da aplicação da medida protetiva 
\} SOBRE "SER MULHER E MÃE" - MOREIRA, T. A. S.; CAVALCANTE, C. P. S.; FERREIRA, D. S.; PAIVA, I. L. \}

DOI: $10.12957 /$ rep.2021.56078

de acolhimento de crianças previstas no Estatuto da Criança e do Adolescente (BRASIL, 1990).

O acolhimento conjunto, por outro lado, não pode ser interpretado como a resolução de todas as questões que envolvem as MSR que desejam permanecer com seus bebês. Mesmo nestes espaços, há desafios, a começar por serem espaços coletivos e compartilhados com outras mulheres e profissionais que não fazem parte da família ou necessariamente pertençam à mesma comunidade. Além disso, é possível que as mulheres sejam abordadas de forma infantilizada, sem que se respeite sua autonomia e valorize seu potencial para exercer a maternidade (ROSALES, 2015). Estas mulheres precisam de espaços que ofereçam proteção, sem cercear suas autonomias, especialmente no que concerne às vivências da sexualidade. A vida sexual delas não deve ser subjugada devido às situações nas quais se encontram. É necessária atenção por parte do poder público em relação ao risco de o acolhimento conjunto funcionar como internato fundamentado na higienização social.

Diante da morosidade do município em prover recursos de moradia para a PoP Rua, o próprio MNPR/RN está se articulando junto a parceiros para executar novas propostas. Há um projeto arquitetônico em curso de moradia compartilhada e sob a gestão da própria Pop Rua, como explica Mamusca:

[...] fazer uma casa de acolhimento pra a família pra casal, pra LGBTs, melhor do que ser casa, da Minha Casa Minha Vida, porque, com certeza, a gente desempregado, com a casa, mas sem um emprego, a gente não vai pra frente. [...] Precisa ter primeiro: assistente social, psicólogo. [...] Trabalho, habitação, cursos qualificantes, tudo isso que é pra mãe poder criar seus filhos. Porque primeiro ela tem que se qualificar, pra poder entrar no mercado de trabalho, na sociedade.

O programa do Governo Federal Minha casa, minha vida possibilitava que, a partir de alguns critérios, pessoas em situação de rua pudessem adquirir imóveis; entretanto, foi criticado por não atender a outras questões que incidem na permanência das pessoas na rua, em particular, a falta de emprego. Mesmo com os cursos profissionalizantes, os estereótipos que associam a Pop Rua à criminalidade cerceiam suas possibilidades empregatícias, já afetadas pela baixa escolaridade e pela pouca qualificação desta população, ambas ocasionadas pelo histórico de negação em relação ao acesso aos direitos fundamentais pelo qual passa esta população, ainda mais no cenário atual de crescimento do desemprego e precarização do trabalho.

Além disso, as mulheres recebem menores salários - mesmo desempenhando as mesmas funções que os homens - e sofrem mais com o desemprego - mesmo sendo parte do estrato social melhor qualificado. Segundo o Instituto Brasileiro de Geografia e Estatística (IBGE, 2019), no quarto 
\} SOBRE "SER MULHER E MÃE" - MOREIRA, T. A. S.; CAVALCANTE, C. P. S.; FERREIRA, D. S.; PAIVA, I. L. \}

DOI: $10.12957 /$ rep.2021.56078

trimestre de 2018, de 52,4\% da população em idade de trabalhar, o grupo feminino responde por $45,6 \%$ do nível de ocupação, enquanto os homens, $64,3 \%$.

Mas, claro que nós não somos burras, entendeu? A gente só não tem oportunidade, mas a maioria dos moradores de rua sabe fazer alguma coisa sim. Eu pelo menos sei fazer doces, aquela ali sabe fazer artesanato. A Maria* é muito boa na cozinha também, culinária. A maioria sabe fazer as coisas. (Mamusca).

Neste cenário, as alternativas de sobrevivência se centram no trabalho pessoal de vender doces associado ao apoio das redes de solidariedade construídas nas ruas da família ao ir residir com sua irmã: "Aí vai ser um babado só! Eu, minha irmã que é lésbica também, vai ser quatro mulheres, quatro mães ela vai ganhar [...] Vai ser uma história muito linda, então" (Mamusca). A experiência da maternidade é, desta forma, um processo também construído através das interações sociais. É importante que essas mulheres sejam reconhecidas como capazes de serem mães, especialmente em um contexto de maiores possibilidades de aborto espontâneo, possível pressão para entrega do bebê à adoção e iminente destituição do poder familiar.

\section{Considerações finais}

A sociedade capitalista produz a desigualdade social e a violência de gênero; logo, as MSR ficam sujeitas a uma gestação não planejada ou não desejada. Esta situação pode interferir na adesão ao pré-natal, potencializar o risco de a mulher desenvolver depressão pós-parto e dificultar o desenvolvimento do vínculo com o bebê. Ademais, mesmo as mulheres que planejam a gravidez ou desejam permanecer com a criança enfrentam dificuldades para exercer a maternidade. Há, assim, uma dupla violência contra as MSR: a gestação compulsória e o risco constante da destituição do poder familiar.

Nota-se que há o desafio de a rede de atendimento do Estado se fazer confiável e segura para as mulheres, diante do histórico de estigmas e de retirada compulsória dos seus filhos. É notável a ausência de políticas públicas que priorizem a maternagem segura e amparada com a manutenção de mães e bebês juntos/as. Por outro lado, Mamusca e P1 são exemplos de que as MSR não estão indiferentes às violações dos seus direitos e se apropriam de recursos para driblar o domínio das suas trajetórias de vida pelo capital. Elas rompem com a heteronormatividade e se utilizam de estratégias informais de proteção para assegurar a convivência com seus fiIhos, como a circulação de crianças e a solidariedade familiar e comunitária. Elas fazem parte de um segmento populacional que enfrenta e faz movi- 


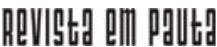

\} SOBRE "SER MULHER E MÃE" - MOREIRA, T. A. S.; CAVALCANTE, C. P. S.; FERREIRA, D. S.; PAIVA, I. L. \}

DOI: $10.12957 /$ rep.2021.56078

mento de resistência ao sistema capitalista pela união e fortalecimento coletivo, pela conquista de justiça, direitos e dignidade fortalecidos por sua participação no MNPR/RN.

Os serviços de acolhimento e demais instituições protetivas de Natal (RN) acolhem os adultos ou as crianças, prioritariamente em espaços separados em descompasso com o direito à convivência familiar e comunitária. Esta lógica vulnerabiliza e dispersa ainda mais as relações familiares porque é difícil para o SGDCA, em especial, o judiciário, compreender que a vivência das famílias pobres é diferente do modelo burguês. Nesses casos, mães, crianças e possíveis demais membros das famílias são penalizados pela insuficiência quantitativa e qualitativa de políticas públicas transversais que entendam às necessidades particulares de cada caso. É fundamental promover a visibilidade destas mães e seus/as filhos/as e a discussão acerca das formas como seus direitos são garantidos ou eclipsados. 
\} SOBRE "SER MULHER E MÃE" - MOREIRA, T. A. S.; CAVALCANTE, C. P. S.; FERREIRA, D. S.; PAIVA, I. L. \} DOI: $10.12957 /$ rep.2021.56078

\section{Referências}

ARRAES AMORIM, A. K. et al. Direitos humanos e população em situação de rua investigando limites e possibilidades de vida. In: NOBRE, M. T.; AMORIM, A. K. A.; MEDEIROS, F. C. de; MATOS, A. C. V. (Org.). Vozes, imagens e resistências nas ruas: a vida pode mais! Natal: EDUFRN, 2019.

BORTOLI, S. R. Mulheres adultas em situação de rua e a mídia: histórias de vidas, práticas profissionais com a população de rua e representações jornalísticas. Tese (Doutorado em Comunicações e Artes) - Universidade de São Paulo, São Paulo, 2016.

BRASIL. Lei no 8.069, de 13 de julho de 1990. Dispõe sobre o Estatuto da Criança e do Adolescente e dá outras providências. Diário Oficial da União, Brasília, 13 jul. 1990.

BRASIL. Decreto no 7053, de 23 de dezembro de 2009. Institui a Política Nacional para a População em Situação de Rua e seu Comitê Intersetorial de Acompanhamento e Monitoramento, e dá outras providências. Diário Oficial da União, Brasília, 24 dez. 2009.

BRASIL. Ministério do Desenvolvimento Social e Combate à Fome. Nota técnica conjunta MDS/MSaúde n. 001/2016. Brasília: Ministério do Desenvolvimento Social e Combate à Fome, 2016.

BRAUN, V.; CLARKE, V. Using thematic analysis in psychology. Qualitative Re-search in Psychology, v. 3, n. 2, 2006. Disponível em: http:// www.informaworld.com/smpp/content ${ }^{\sim} \mathrm{db}=$ all ${ }^{\sim}$ content $=\mathrm{a} 795127197^{\sim}$ frm=titlelink. Acesso em: 8 nov. 2020.

CALDEIRA, Z. F. O governo dos corpos das "mães do crack": a produção de um novo inimigo social. Revista Episteme Transversalis, v. 10, n. 1, 2019.

CONANDA. Nota pública do Conanda de repúdio à retirada compulsória de bebês de mães usuárias de substância psicoativas, 2017. Disponível em: http://www.direitosdacrianca.gov.br/documentos/notas-publicas-dosconanda. Acesso em: 8 jan. 2019.

COSTA, S. L. da et al. Gestantes em situação de rua no município de Santos, SP: reflexões e desafios para as políticas públicas. Saúde e Sociedade, v. 24, n. 3, 2015. Disponível em: http://dx.doi.org/10.1590/S010412902015134769. Acesso em: 8 jan. 2019.

CRONEMBERGER, I. H. G. M.; TEIXEIRA, S. M. Famílias vulneráveis como expressão da questão social, à luz da política de assistência social. Revista Eletrônica: Informe Eletrônico, v. 1, n. 1, 2013. Disponível em: https:// revistas.ufpi.br/index.php/economiaufpi/article/view/1267. Acesso em: 8 jan. 2019. 
\} SOBRE "SER MULHER E MÃE" - MOREIRA, T. A. S.; CAVALCANTE, C. P. S.; FERREIRA, D. S.; PAIVA, I. L. \} DOI: $10.12957 /$ rep.2021.56078

DIAS, R. T. Estigma relacionado a usuários de drogas: um estudo das crenças de profissionais de saúde. Dissertação (Mestrado em Psicologia) - Programa de Pós-Graduação em Psicologia, UFJF, 2019.

GOMES, J. D. G. Relatório de pesquisa: primeira infância e maternidade nas ruas da cidade de São Paulo, 2018. Disponível em: https://issuu.com/ cdh.luiz.gama/docs/relatorio_primeira_infancia. Acesso em: 8 jul. 2019.

GONTIJO, D. T.; MEDEIROS, M. "Tava morta e revivi": significado de maternidade para adolescentes com experiência de vida nas ruas. Cadernos de Saúde Pública, v. 24, n. 2, 2008.

GROULX, L. Contribuição da pesquisa qualitativa à pesquisa social. In: POUPART, J.; COLS (Org.). A pesquisa qualitativa: enfoques epistemológicos e metodológicos. Petrópolis: Vozes, 2010.

GUILLAUMIN, C. Prática do poder e ideia de natureza. In: FERREIRA, V.; ÁVILA, M. B.; FALQUET, J.; ABREU, M. (Org.) O patriarcado desvendado: teorias de três feministas materialistas. Recife: SOS Corpo, 2014.

IBGE. Pesquisa Nacional por Amostra de Domicílios: PNAD Contínua. Período: quarto trimestre de 2018. Rio de Janeiro: IBGE, 2019.

KUYAVA, A. C. L. S. O cotidiano de gestantes usuárias de crack. Dissertação (Mestrado em Enfermagem) - Universidade Federal do Rio Grande do Sul, Porto Alegre, 2013.

MACHADO, R. Genealogia do Poder. In: FOUCAULT, M. Microfísica do poder. Rio de Janeiro: Graal, 1979.

MALHEIRO, L. S. B. Tornar-se mulher usuária de crack: trajetórias de vida, cultura de uso e política sobre drogas no centro de Salvador, Bahia. Dissertação (Mestrado em Antropologia) - Programa de Pós-Graduação em Antropologia, UFBA, 2018.

MARTINS, J. de S. Exclusão social e a nova desigualdade. São Paulo: Paulus, 1997.

RIOS, A. G. O fio de Ariadne: sobre os labirintos de vida de mulheres grávidas usuárias de álcool e outras drogas. Dissertação (Mestrado em Saúde Coletiva) - Universidade Estadual de Campinas, Campinas, 2017.

ROSALES, M. R. Mujeres invisiblizadas, madres interpeladas: producción de subjetividad en un hogar para mujeres con hijas e hijos en situación de calle. Tese (Mestrado em Psicologia e Educação) - Universidad de la República, Uruguay, 2015.

SARAIVA, V. C. dos S. Repensando a circulação e a adoção de crianças negras na família brasileira. Revista Em Pauta, v. 18, n. 45, 2019. Disponível em: https://www.e-publicacoes.uerj.br/index.php/revistaempauta/article/ view/47216. Acesso em: 8 fev. 2020. 


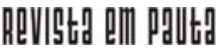

\} SOBRE "SER MULHER E MÃE" - MOREIRA, T. A. S.; CAVALCANTE, C. P. S.; FERREIRA, D. S.; PAIVA, I. L. \}

DOI: $10.12957 /$ rep.2021.56078

SAVIANI, D. A pedagogia histórico-crítica, as lutas de classe e educação escolar. Revista Germinal: Marxismo e Educação em Debate, v. 5, n. 2, 2013. Disponível em: https://pdfs.semanticscholar.org/b70a/ cede43b1572768eceae052d4327253b7e190.pdf. Acesso em: 28 fev. 2020. VERGARA, E. M. Empoderamento político na gestão de direitos sociais. In: NOBRE, M. T. et al. (Org.). Vozes, imagens e resistências nas ruas: a vida pode mais! Natal: EDUFRN, 2019.

DOI: $10.12957 /$ rep.2021.56078

Recebido em 09 de março de 2020.

Aprovado para publicação em 10 de agosto de 2020.

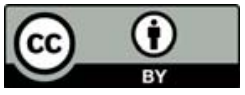

A Revista Em Pauta: Teoria Social e Realidade Contemporânea está licenciada com uma Licença Creative Commons Atribuição 4.0 Internacional. 